\title{
REFORMAS POMBALINAS E ADMINISTRAÇÃO JURÍDICO-POLIITICA NA CURITIBA DO SÉCULO 18 (1769-1777)
}

http://dx.doi.org/10.21527/2176-6622.2021.56.10386

Recebido em: 20/3/2020

Aceito em: $12 / 8 / 2020$

Vanessa Caroline Massuchetto

Universidade Federal do Paraná (UFPR). Praça Santos Andrade, 50 - Centro. Curitiba/PR, Brasil. CEP 80060-000. http://lattes.cnpq.br/2944927518844355. https://orcid.org/0000-0003-0390-7890. vanessa.massuchetto@gmail.com

\section{RESUMO}

O presente trabalho buscou manter atenção a quais foram os reflexos na América Portuguesa das reformas empreendidas no Império Português durante o governo de D. José I, sobretudo sob mando do Marquês de Pombal. O objetivo fora o questionamento acerca do alcance dessas medidas, conhecidas enquanto racionalizadoras e modernizadoras dos aparatos jurídico-político-administrativos. Privilegiando-se o âmbito jurídico-administrativo, sobretudo as alterações intentadas pela Lei da Boa Razão (1769), buscou-se, na documentação da Câmara Municipal da Vila de Curitiba, reproduções dos elementos lançados enquanto inovadores ao período. $O$ enfoque principal é dado às limitações interpretativas da cultura jurídica circulante no período, bem como a configuração de um modelo de administração político-jurídica mais ativa sobre a atuação dos oficiais locais. O recorte temporal é o período entre 1769 e 1777, compreendendo, pois, o ano de publicação da supracitada lei e o fim do reinado de D. José I.

Palavras-chave: Vila de Curitiba; período pombalino; Lei da Boa Razão.

POMBALINE REFORMS AND LEGAL-POLITICAL ADMINISTRATION IN 18 ${ }^{\text {TH }}$ CENTURY CURITIBA (1769-1777)

\section{ABSTRACT}

This article sought comprehend the reflexes of the reforms made in the Portuguese Empire by the Marquis de Pombal during the government of D. José I, and track which of them arrived in Portuguese America. The aim was to question the reach of these policies, widely known as rationalizing and modernizing of the legal-political-administrative apparatus. Focusing on the legal-administrative area, especially the changes made by the Law of Good Reason (1769), reproductions of the innovators were sought in the historical sources of the Curitiba's Council. The main focus is the interpretative limitations of the legal culture circulating in the period and the configuration of a more active political-legal administration model on the local performance of the officials. The temporal cut is between the years 1769 and 1777 , comprising the year of publication of the aforementioned law and the end of the reign of D. José $I$.

Keywords: Village of Curitiba; pombaline period; Law of Good Reason. 


\section{INTRODUÇÃO}

Em fins dos anos setecentos, as atitudes empreendidas pelo Marquês de Pombal ${ }^{1}$, secretário de Estado ${ }^{2}$ durante o reinado de Dom José I, intentaram alterar determinadas lógicas próprias da sociedade corporativa. O foco era a modernização e a racionalização do aparato político-jurídico-administrativo do Império Português, ensejando, entre várias consequências, a centralização política do poderio monárquico, a luta contra os poderes concorrentes, a burocratização do aparelho administrativo, a reforma das instituições de educação, a expulsão da Companhia de Jesus do território americano, o fomento à mercantilização e o desenvolvimento do poder de polícia. Não se pode descartar que a imposição dessas ideias direcionava a uma lógica então desconhecida e significou para o Império uma das grandes descontinuidades pelas quais o modernismo se apontava.

A presente pesquisa busca lançar olhares aos reflexos de algumas dessas reformas na prática jurídica e administrativa da América Portuguesa, selecionando especificamente a Câmara Municipal da Vila de Nossa Senhora da Luz dos Pinhais de Curitiba. Por ser um território fronteiriço e configurar uma região que destoava da maioria por não ser localizada em área marítima (além de estar em um planalto de difícil acesso), a Vila de Curitiba é bastante significativa para a compreensão do funcionamento das redes de poder existentes no Antigo Regime Português. O foco privilegiado é dado aos aspectos tangentes à administração político-jurídica, sobretudo as balizas de seleção das fontes do direito intentadas pela Lei da Boa Razão e o direito de organização citadina, sentidos pelo organismo jurídico-político-administrativo local.

Estabelecido o recorte temporal de 18 de agosto de $1769^{3}$ até 24 de fevereiro de $1777^{4}$, a pesquisa foi desenvolvida a partir da busca em correspondências, provisões, atas do Conselho, provimentos, ordens e outros documentos compilados por Francisco Negrão no Boletim do Archivo Municipal de Curytiba e as correspondências reunidas dentre os Documentos Interessantes para a História e Costumes de São Paulo. A investigação desenvolvida com o auxílio dos documentos compilados mantém foco no trânsito das políticas pombalinas (acompanhadas, ou não, de mudanças ou reformas) realizado pelos oficiais régios da Ouvidoria de Paranaguá e do Governo da Capitania de São Paulo em direção à Câmara Municipal da Vila de Curitiba. A gama de documentos existentes no Boletim do Archivo Municipal de Curytiba serve de guia, também, ao estudo da transmissão dessas políticas (e alguma possível imposição dessas reformas) pelos oficiais daquele Conselho Camarário aos moradores por intermédio de instrumentos que digam mais respeito à organização da Vila.

Cabe destacar que a perspectiva tomada pela presente pesquisa no que se refere ao tema das relações entre metrópole e colônia segue o caminhar da historiografia na última década, isto é, que não as fundamenta a partir do viés centralização-descentralização. É cediço que este formato de relações centro-periferia, clássico para a explicação dos fenômenos havidos na América Portuguesa, "não é mais suficiente para explicar a complexidade das redes e conexões que ligaram os diferentes domínios ultramarinos, entre si e com o centro da monarquia" (BICALHO, 2009, p. 91). O conceito de Império Marítimo Português (BOXER, 2008) surgiu na tentativa de se compreender o-amplo e plural - complexo conjunto de relações havidas na dinâmica ultramarina portuguesa, abarcando a lógica das redes imperiais, inter-relações tecidas entre as colônias portuguesas por meio de trocas de oficiais régios, trocas comerciais e, para além, trocas de aspectos culturais, de forma a conectar os locais do império ultramarino e manter tanto a flexibilidade quanto a rigidez desse sistema. A compreensão deste espectro traz à tona a evidência da porosidade do sistema como um todo, o que lhe conferia equilíbrio, possibilitando que essa situação perdurasse até a primeira metade do século 19 (BICALHO, 2009).

\footnotetext{
Sebastião José de Carvalho e Melo foi nomeado Marquês de Pombal em 1769.

2 Desde o ano de 1736, durante o reinado de Dom João V, os organismos de assistência real foram ordenados em três Secretarias de Estado: dos Negócios Interiores do Reino, dos Negócios da Marinha e Domínios Ultramarinos e dos Negócios Estrangeiros e da Guerra. Com a assunção de D. José I em 1750, foi atribuída a Sebastião José esta última Secretaria. Até 1756 o Marquês de Pombal, embora detivesse competência específica, influenciou em grau considerável âmbitos da administração portuguesa que não faziam parte do seu espaço de atribuições. Após a morte do secretário dos Negócios Interiores do Reino, a demissão do secretário dos Negócios da Marinha e Domínios Ultramarinos, ambas ocorridas em 1756, e a criação da Secretaria de Estado adjunta em 1759, foram esses cargos atribuídos a oficiais que fossem, de alguma forma, ligados a Sebastião José, proporcionando-lhe maior influência em todas as Secretarias (MARCOS, 2006).

3 Publicação da Lei da Boa Razão.

Morte de Dom José I e consequente retirada do Marquês de Pombal do organismo régio português.
} 


\section{TRAÇOS GERAIS DAS POLÍTICAS POMBALINAS}

Embora grande parte das teorias que dão fundamento a uma nova ordem jurídica e social terem sido pensadas ao longo dos séculos 16 e 17, ou até mesmo no 18, a explosão dos efeitos práticos e a implicação de mudanças na realidade concreta, principalmente da Europa, ocorreram apenas em fins dos anos setecentos e de maneira desigual em cada locus. Na linha de Paolo Grossi $(2007,2008)$, esse caminhar dos desdobramentos modernos foi bastante lento, desembocando em consolidação desse processo em fins do 18, principalmente com as revoluções burguesas. Ao longo deste século houve, gradativamente, manifestações do que o autor denomina de iluminismo político-jurídico, trazendo à tona características modernas e formulação de discursos contrários à ordem político-jurídica do período anterior, a que se intentava suprimir.

As principais tendências do iluminismo político-jurídico mantinham fulcro na absoluta importância do direito. Todo o regramento do ordenamento jurídico passaria paulatinamente a ser posto na competência do Estado, uma vez que este seria o detentor do poder, construindo o discurso que intentava realizar uma vinculação visceral do direito com o poder, separando-o do social. Como consequência desta separação, haveria uma redução de complexidade do direito, atribuindo toda sua atividade à lei ${ }^{5}$, deixando, assim, ao Antigo Regime, a dimensão coletiva de sociedade (GROSSI, 2008).

Em Portugal a dispersão dessas ideias ocorreu por, basicamente, todo século 18, sobretudo na segunda metade (SILVA, 2000), com Dom José I e Sebastião José de Carvalho e Melo. ${ }^{6}$ As medidas nesse período empenhadas são normalmente enquadradas na moldura governativa do despotismo esclarecido, por manter uma "política de reforma disfarçada, como ditada pela prudência, por instituições e linguagens antigas" (MAXWELL, 1996, p. 10). A mentalidade do Marquês de Pombal era tendencialmente racionalista, o que o fez estimular a prática de algumas das ideias europeias pensadas no século 17, inaugurando, ao longo do século 18, conforme Rui Manuel de Figueiredo Marcos (2006, p. 11), algumas ideias novas, "um cotejo novo, mas cujos figurantes trajavam à antiga.".

No cenário político-jurídico-administrativo, as políticas pombalinas mantiveram foco principalmente em medidas que, ao período, representavam a racionalização dos aparatos de governo. Neste esforço, viriam a necessidade de centralização administrativa e o ímpeto de ordem social (MARCOS, 2006), fazendo com que os aparatos de governo do Império Português passassem gradativamente a exercer uma administração ativa, que, acreditando nas "razões do Estado"7, buscava uma organização da sociedade centrada na figura do rei (SUBTIL, 1998). Nesse empenho, houve tentativa de supressão de instituições e de submissão das esferas de poder aos mandos régios (ANTUNES, 2011).

Ancorado nesses fundamentos, houve o desenvolvimento do que Airton Cerqueira Leite Seelaender (2009) denomina de polícia do reino. Ou seja, uma noção que permeia um governo embasado na regulação da convivência, na repressão de comportamentos e na crença de que para proteção de uma "boa ordem" era aceitável que houvesse a relativização de direitos costumeiros e de privilégios, estamentos, municipalidades e corporações. A criação da Intendência Geral da Polícia, em 1760, e a criação de leis de polícia, demonstram a intenção de maior controle da sociedade portuguesa, na intenção de restaurar a boa ordem, proteger o território do Império, reforçar os exércitos, instituir companhias coloniais e fiscalizar os municípios. A Coroa passava, pois, da administração mais passiva a atuações mais ativas, assumindo várias políticas preocupadas com o crescimento populacional e com finalidade de maior arrecadação.

Essa característica de "Estado de polícia" teve intensos reflexos em uma perspectiva macro nos espaços ultramarinos. A tentativa de centralização atraiu à competência régia a supervisão a determinadas práticas administrativas das localidades, sobretudo àquelas referentes a saneamento, urbanismo e economia política. A tentativa de mudança - ou, como coloca Magnus Pereira (2003), de atualização - de certas formas de admi-

\footnotetext{
A era das codificações representou a concretização desse reducionismo. Nas palavras de Grossi (2008, p. 97): “O velho pluralismo jurídico, que tinha nos seus ombros mais de dois mil anos de vida, mesmo com várias vicissitudes, passa a ser estrangulado em um rígido monismo".

6 Considerando-se que "Pombal deve ser entendido como um referencial para as mudanças amplas que tiveram lugar no reinado de D. José I." (ANTUNES, 2011, p. 16).

O termo segue entre aspas para marcar sua historicidade.
} 
nistração municipal, ou da maneira do viver em cidade, fez com que a Coroa interferisse principalmente nas questões de salubridade e em normas de abastecimento municipal (PEREIRA, M.; SANTOS, 2003).

Especificamente no que se refere à administração da justiça, Marcos (2006) identifica que a atividade legislativa pombalina, a partir de 1750, esteve mais direcionada no sentido de conter determinadas crises nos setores financeiro, militar e alfandegário do Império (portanto, sem práticas com grandes pretensões reformistas). Foi a partir de 1766 que se começou a trazer à tona a ideia de introjeção da racionalidade no aparato político-jurídico-administrativo português. Neste segundo movimento foi publicado um dos instrumentos mais emblemáticos da introdução de características modernas na administração da justiça do Império Português: a Lei de 18 de agosto de 1769 (PORTUGAL, 1829).

O maior esforço desta Lei foi a tentativa de uma reforma jurídica sobretudo nas fontes do direito. Esboçara uma espécie de guia com preceitos novos para interpretação do próprio direito, tendo como objetivo realizar uma reforma com base na revisão da hierarquia das fontes do direito para reduzir a complexidade própria do Antigo Regime por meio da mitigação da pluralidade (ANTUNES, 2011; MARCOS, 2006). Essa lógica já havia sido intentada anteriormente - assim como o foi posteriormente ${ }^{8}$-, sendo uma destas medidas realizada pouco tempo antes, em maio de 1769 , com o Alvará régio que determinava a interpretação das leis como atributo apenas da competência dos "Legisladores Supremos". Igualmente, em 1768, com a Lei de 3 de novembro, houve tentativa de sobreposição do direito régio português a outros vigentes no reino, principalmente o direito romano. ${ }^{9}$

A Lei de 18 de agosto de 1769, pois, representou uma das mais ambiciosas, intentando balizar os modos de intepretação às fontes do direito, fixando o direito pátrio como hierarquicamente superior aos demais na leitura do direito vigente (COSTA, 1996). A pretensão era excluir as "interpretações abusivas, que offendem a Magestade das Leis" (PORTUGAL, 1829, p. 408). Excluía a aplicação dos comentários de Bártolo ao corpus iuris civilis, reservando o uso do direito romano somente em casos de omissão do direito pátrio e conforme a boa razão. Limitava a utilização do direito canônico aos tribunais eclesiásticos, e estabelecia aplicabilidade somente dos costumes com mais de cem anos de existência e que estivessem conforme as leis régias e a boa razão (SILVA, 2000). Uma outra providência desta Lei foi a inclusão da legislação das "Nações mais iluminadas" como instrumento fonte do direito (PORTUGAL, 1829, p. 408).

A expressão "boa razão" não era, neste momento da publicação da Lei de 18 de agosto de 1769, nova. Antes disso, era utilizada em vários mandos régios e, inclusive, nas Ordenações Filipinas no sentido corrente de "razão natural" e de "justa razão". Quando, entretanto, utilizada como condicional em vários aspectos da referida lei - a ponto de fazer com que os juristas do século 19 lhe dessem o nome de "Lei da Boa Razão" pelo maciço aparecimento da expressão -, passaria a reter um significado novo. Em um primeiro momento este novo sentido foi expresso na própria lei, e deveria ser

\footnotetext{
Ou aquella boa razão, que consiste nos primitivos principios, que contém verdades essenciaes, intrinsecas, e inalteraveis, que a Ethica dos mesmos Romanos havia estabelecido, e que os Direitos Divino, e Natural, formalizarão para servirem de Regras Moraes, e Civís entre o Christianismo: Ou aquella boa razão, que se funda nas outras Regras, que de universal consentimento estabeleceo o Direito das Gentes para a direcção, e governo de todas as Nações civilizadas: Ou aquella boa razão, que se estabelece nas Leis Politicas, Economicas, Mercantîs, e Maritimas, que as mesmas Nações Christãs tem promulgado com manifestas utilidades, do socego público, do estabelecimento da reputação, e do aumento dos cabedais dos Póvos, que com as disciplinas destas sabias, e proveitosas Leis vivem felices á sombra dos Thronos, e debaixo dos auspícios dos seus respectivos Monarcas, e Principes Soberanos: [...] (PORTUGAL, 1829, p. 411).
}

\footnotetext{
O que traça direcionamento a duas conclusões: (i) que a Lei da Boa Razão não obteve a eficácia pretendida ou (ii) que seu objetivo era puxar o gatilho de uma reforma que deveria ser feita pela reprodução de seus efeitos em legislação posterior (ANTUNES, 2011).

9 Essa medida tentou definir que apenas seria cabível recurso de revista de decisões judiciais que trouxessem manifesta nulidade ou justiça notória - até aqui as Ordenações já definiam - com relação ao direito estritamente português, excluindo a possibilidade de recurso com fulcro na violação de normas de direito romano (MARCOS, 2006).
} 
Em 1772, os Estatutos Novos da Universidade de Coimbra trouxeram à tona uma definição mais específica. ${ }^{10} \mathrm{O}$ que carregaram de mais inovador ao momento histórico em que foram publicados e passaram a reformular os estudos realizados na Universidade de Coimbra foram o método e a orientação de ensino (COSTA, 1996). Sob influência das universidades alemãs, o método proposto foi o "sintético-demonstrativo-compendiário", em oposição ao silogismo, bastante comum no período. ${ }^{11}$

O segundo livro dos Estatutos estabelecia o currículo das Faculdades de Leis e de Cânones juntamente com regras que intentavam guiar o modo como o ensino do direito deveria ser realizado. Sobre o direito natural, às leis pátrias e às leis das Nações Civilizadas foi exposto a referência ao "uso moderno": "Indagarão o Uso Moderno das mesmas Leis Romanas entre as sobreditas Nações, que hora habitam a Europa. E descobrindo, que Elas as observam, e guardam ainda no tempo presente;" (PORTUGAL, 1772, L. II, p. 272). Ainda, esclarecendo o que seria esse uso:

Para se instruírem no dito Uso Moderno, se aproveitarão os Professores do útil, e apreciável trabalho, que para o mesmo fim se acha já feito por grande número de Jurisconsultos em diferentes Livros; dos quais uns são escritos pela ordem, e serie dos Livros, e Títulos, e das Leis do Direito Civil Romano; e outros são formados por Metodos arbitrários: [...] De todos os sobreditos Livros extrairão os referidos Professores a Doutrina do dito Uso Moderno (PORTUGAL, 1772, L. II, p. 273-274).

Com base neste trecho, pode-se afirmar que a boa razão, inaugurada pela Lei de 18 de agosto de 1769, tinha ligação direta com as doutrinas dos grandes pensadores da escola alemã do usus modernus pandectarum (COSTA, 1996). De acordo com estes, a recepção do direito romano deveria ser realizada a partir de uma recepção prática, ou seja, os textos romanos teriam validade à tradição jurídica local na medida em que fossem úteis para resolver questões práticas. Em outros termos, seriam filtrados pela realidade por meio do instrumental disponível na experiência jurídica local (HESPANHA, 2005).

Assim, percebe-se que o foco principal das medidas postas em marcha a partir da década de 60 do século 18 era a maior difusão e aplicabilidade do direito régio. O objetivo da Lei da Boa Razão foi legitimar a lei régia como fonte principal do direito, salientando os princípios do direito natural, de forma a tentar uma maior aplicação, esforço este acompanhado dos Estatutos Pombalinos de reforma da Universidade de Coimbra em 1772 e a consequente introdução do estudo ao direito régio. Houve, pois, neste período, uma exaltação do direito natural e tentativa de formação da consciência de um direito "pátrio" (SILVA, 2000).

\section{ADMINISTRAÇÃO POLÍTICO-JURÍDICA E OS ORGANISMOS INSTITUCIONAIS LOCAIS DA AMÉRICA PORTUGUESA}

Passando-se aos organismos locais que recepcionaram estes intentos racionalizadores e modernizadores, é importante mencionar que a estrutura local de administração da justiça ao longo de todo o Império UItramarino na América Portuguesa era o Conselho Municipal, surgido nas comunidades locais portuguesas pela finalidade de proteção por meio do estabelecimento de uma ordem interna própria. Buscando uma espécie de extensão do poder central, a metrópole paulatinamente estabeleceu forais com esses Conselhos e passou a manter forças militares e serviços nas localidades, de forma a tornar o reino legítimo naquele locus. Assim, tornaram-se o espaço pelo qual os mandos régios eram difundidos ao longo das vilas do Império Ultramarino, contando normalmente com o auxílio e fiscalização de oficiais superiores aos Conselhos, sobretudo dos ouvi-

\footnotetext{
${ }_{10}$ Estes instrumentos foram produtos da Junta de Providência Literária formada em 1770, cuja competência era analisar as causas da decadência do ensino universitário e propor medidas adequadas de reformas, e alcançaram extensa aplicabilidade prática, influenciando a produção doutrinal dos juristas do fim do século 18 e do 19. Desta Junta, ainda, houve a publicação do Compêndio Histórico da Universidade de Coimbra, em 1771, no qual houve a reafirmação de várias medidas contidas na obra de Luis Antonio Verney. Este Compêndio apontou como um dos graves defeitos do ensino jurídico a preferência absoluta que se realizava à aplicação do direito romano - neste inclua-se a interpretação extensa aos comentários de Bártolo e ao método bartolista - em detrimento dos direitos pátrio e natural (COSTA, 1996).

${ }^{11}$ Neste ponto, a obra de Verney influenciou bastante para a passagem do estilo de ensino por meio da retórica para um enfoque no modo de falar mais conciso e sintético, uma vez que era por intermédio deste formato que seria possível sair do âmbito das especulações infundadas e adentrar ao território da razão experimental. Isto é, o enfoque principal era um método que a boa razão indicasse ser útil para atingir a "verdade" (CARVALHO, 2005).
} 
dores (MONTEIRO, 2001) ${ }^{12}$. Nessa perspectiva, os municípios foram se tornando organismos estruturais ao Império, posto que, ao mesmo tempo em que mantinha, ao menos simbolicamente, o braço real na localidade, assegurava a autonomia nas decisões locais (SANTOS; SANTOS, 2003).

Segundo Maria Fernanda Bicalho (2001), as câmaras significaram - sobretudo em virtude da uniformidade institucional posta por meio das atribuições dos oficiais estabelecidas nas Ordenações (SANTOS, 2000) -, um órgão fundamental à sistemática de governo do Antigo Regime português no que se refere à sua construção, manutenção e continuidade. ${ }^{13}$ Os personagens que compunham o Conselho eram, geralmente, "cidadãos comuns, não treinados nos caminhos da lei, que se dispunham a servir a comunidade por um ano" (SCHWARTZ, 2011, p. 30-32), contudo frequentemente os oficiais eram reconduzidos aos seus cargos, o que Ihes permitia permanecer por mais de um ano no exercício. ${ }^{14}$

Com essa configuração, e considerando a ideia de que as relações entre a metrópole e a América Portuguesa baseavam-se numa rede de interdependência, pode-se afirmar que o direito praticado conforme as particularidades locais configuravam um pluralismo efetivo, tendo em vista que as Ordenações - conhecidas como as leis "gerais" do Império - não impunham a totalidade normativa, nem caminhavam a esta pretensão (PEREIRA, 2009). Nesse viés, a montagem do Império Português ultramarino era feita com a construção de centros periféricos de poder concentrados nesses Conselhos Municipais, detentores de autonomia e poder de negociação com a coroa (BICALHO, 2009). Nos termos da perspectiva de Schwartz (2011), os órgãos administrativos instalados na América Portuguesa tentavam reproduzir as construções existentes em Portugal, mesmo que repletos de antagonismos. A colônia não era uma organização exatamente nos termos do que pautava a Coroa à metrópole, dando espaço à alteridade (FURTADO, 2009). Não se pode acreditar em uma autonomia absoluta dessas instituições, muito menos que eram completamente independentes da metrópole; o que se verifica é uma amplitude nas atribuições conselhias e na autonomia para que a instituição de ordens régias fosse feita conforme os interesses locais, configurando uma autonomia relativa.

\section{REFLEXOS DAS REFORMAS JURÍDICAS POMBALINAS NA VILA DE CURITIBA}

Criada formalmente em 1693 a partir de um requerimento jurídico elaborado pelos membros da povoação ${ }^{15}$, a Vila de Nossa Senhora da Luz dos Pinhais de Curitiba foi comprada pelo rei de Portugal no início do século seguinte, em 1711. Nesse caminhar, foi ao longo do século 18 que a Câmara seguiu, gradativamente, tomando forma de organismo de administração ativa, e, em razão disto, é, em grande medida, representativa do desenvolvimento urbano de várias outras localidades da colônia que, de igual maneira, obtiveram estruturação de aparatos político-jurídico-administrativos neste século. Insta salientar o caráter paulatino, mesmo porque, segundo sustentado por Magnus Pereira, até os anos setecentos as atribuições camarárias não eram voltadas à realização de serviços "públicos" à população da Vila, tanto que sua estrutura não fora preparada para tal execução (PEREIRA; SANTOS, 2003).

\footnotetext{
12 Os ouvidores, por terem maior conhecimento da legislação (uma vez que detinham necessariamente a formação bacharelesca) e maior contato com conselhos régios, confrontavam algumas vezes os juízes ordinários. Para além, o espaço de exercício dos Conselhos camarários estava limitado, igualmente, pelos Tribunais da Relação (instância superior recursal), e também cabe citar a justiça privada, ou justiça senhorial, jurisdições que estavam fora do alcance da câmara municipal e normalmente eram regidas pelo mandonismo rural (WEHLING; WEHLING, 1999).

${ }^{13}$ Inclusive, foram essas as principais instituições administrativas da colonização que construíram e mantiveram, até pelo menos o século 18 , estrutura de administração ambígua do Império Ultramarino (BICALHO, 2001).

${ }^{14}$ A ausência de treinamento, conforme "o caminho da lei", significava a falta do bacharelado em direito, o que não remete a esses oficiais a característica necessária e indissociável da rusticidade. Embora desprovidos da formação teórica, consoante defende Luís Fernando Lopes Pereira (2009), o exercício prático usualmente fornecia aos oficiais dos conselhos modos de apreensão das técnicas da instituição. Ou seja, em que pese não detivessem características de "letrados", não significa que seriam ignorantes quanto aos regramentos do Império, rústicos ou, até mesmo, analfabetos.

${ }^{15}$ As origens do povoamento de Curitiba ocorreram em meados do século 17 em razão de notícias de existência de ouro nestes territórios. Neste momento houve concessão de terras da região a título de sesmarias e a instalação de pequenos povoados, sendo a tomada de posse, com elevação do povoado à condição de vila e levantamento do pelourinho por Gabriel de Lara em nome de Marquês da Cascais (donatário de quase a integralidade das terras meridionais da América Portuguesa), realizada apenas em 4 de novembro de 1668. Posteriormente, a requerimento dos moradores do povoado - fundamentado nas Ordenações Filipinas -, em 1693 houve a eleição do Concelho Municipal da Vila de Curitiba e a criação das justiças (NEGRÃO, v. I, 1906).
} 
No que se refere à circulação de regramentos régios nas práticas camarárias, Luis Pereira (2013) expõe que, entre os documentos atinentes às receitas e despesas da Câmara Municipal de Curitiba, compilados no Boletim do Archivo Municipal de Curytiba, identificam-se pagamentos realizados em razão da compra, pelo Conselho, de uma coleção dos livros da referida legislação régia em 1704 (NEGRÃO, v. VI, 1908), bem como entre 1706 e 1709. Este contato com a legislação imperial pode ser comprovado, também, pela documentação mantida no acervo do Arquivo Público do Estado do Paraná, quais sejam, os processos judiciais formalizados desde, pelo menos, $1697^{16}$, além de a documentação constante do Boletim do Archivo Municipal de Curytiba conter várias menções de Francisco Negrão aos inventários formalizados já desde 1693. Isso traz evidências contrárias às características da oralidade, da "rusticidade" (de oficiais leigos) e da aplicação isolada dos costumes e tradições locais direcionados a localidades fronteiriças, relacionando ao que Pereira salienta sobre o considerável grau de tecnicidade reproduzida nos atos institucionais da vila. Por mais que desprovidos, num primeiro momento, do conhecimento técnico letrado, os oficiais "vão a eles se familiarizando com o tempo, aprendendo a manejar as técnicas e a respeitar os procedimentos da esfera judicial que se montava nas Câmaras." (PEREIRA, 2013, p. 592).

É salutar que seja ressaltada a importância do que foram as fontes da Câmara Municipal de Curitiba para contradizer a crença de que a aproximação dos oficiais desta Vila para com o direito régio e a burocratização própria dos aparatos administrativos imperiais portugueses, teria vindo tão somente com a correição do ouvidor Pardinho em 1721. Os provimentos de correição deixados por este ouvidor não foram, pois, o primeiro contato dos oficiais camarários da Vila de Curitiba com os regramentos do Império português, todavia reconhece-se a importância desta correição, uma vez que "foram elementos centrais na difusão dos procedimentos cabíveis às Câmaras e regulamentados pelas Ordenações" (PEREIRA, 2013, p. 598). ${ }^{17}$

Nomeado ouvidor da Capitania de São Paulo pela administração jurídico-política régia em 1717, o Ouvidor Raphael Pires Pardinho promoveu correições em toda sua jurisdição ao longo dos primeiros anos a partir da data em que tomou posse do cargo. ${ }^{18} \mathrm{Em} 1720$ compareceu à Vila de Nossa Senhora da Luz dos Pinhais de Curitiba e deixou seus Provimentos em 26 de janeiro de 1721, contendo, em carta ao Rei de Portugal, suas impressões comparativas ao restante das vilas do Império. Em várias passagens expressou que os oficiais camarários não realizavam determinadas atribuições de acordo com o que normalmente se fazia em outras vilas do Império, por exemplo, o costume de não se abrir devassas ${ }^{19}$, ou nas que foram abertas não havia culpados em razão da suposta "malícia dos juízes". Isto é, os membros camarários tinham conhecimento das atribuições no que diz respeito ao processamento de crimes, mas talvez existissem interesses locais relacionados a determinadas causas que os fizessem acreditar ser mais vantajoso ou sem necessidade o seguimento dos regramentos nos exatos termos conforme expostos nas Ordenações. Nesse sentido, o Ouvidor demonstrou, já ao início de seus provimentos, a preocupação em deixar minuciosidades acerca do padrão havido no Império Português, mesmo porque era a primeira correição realizada nestas localidades e, em tese, existiria a necessidade de deixar "com mais extensão estes capítulos, para que observando os evitem as desordens em que até agora alguns tropeçavam por ignorância, e os maliciosos, não tenham já a desculpa de ignorantes. (Esta é a primeira correição)" (NEGRÃO, v. VIII, 1924, p. 6).

Em geral, pode-se afirmar que o objetivo dessas correições era manter uma coerência no tocante à organização (administrativa, judicial, política, urbanística, etc.) e aos aspectos da vida citadina (até mesmo no que

\footnotetext{
${ }^{16}$ Como os autos de inventário de Balthazar Carrasco dos Reis, mantido no acervo do Fundo do Poder Judiciário Estadual sob o códice BR PRAPPR PB045 PC01.1.

17 É importante mencionar que estes mesmos provimentos foram repetidos em seu conteúdo até o século 19, quando ocorreu a mudança nos organismos de administração jurídico-política pela legislação imperial (SANTOS, 2000).

${ }^{18}$ Embora tal correição localize-se numa temporalidade que extrapola os limites do recorte selecionado para o presente trabalho, cabe manter saliência de que foram reproduzidos pela maioria dos ouvidores posteriores ao Pardinho. Inclusive, nos períodos em que a Vila de Curitiba restou sem correições, eram tais provimentos relidos pelos oficiais camarários ao início de cada ano (NEGRÃO, v. VIII, 1924).

${ }^{19}$ Quanto a este mando específico, o ouvidor exemplificou os procedimentos que deveriam ser seguidos e ressaltou a importância e se tirarem devassas gerais a cada início de ano, as denominadas janeirinhas. Embasando-se neste provimento, pode-se resgatar o viés de Mario Sbriccoli, segundo o qual a justiça criminal passava a ser visualizada como um importante fator social e, portanto, deveria ser trazida para o interior dos aparatos régios de administração da justiça para que fossem solucionadas, retirando da esfera puramente privada (NEGRÃO, v. VIII, 1924; PEREIRA, 2013; SBRICCOLI, 2009).
} 
se refere à obrigatoriedade das festas católicas, determinando o comparecimento dos oficiais e moradores a estes eventos) (NEGRÃO, v. VIII, 1924); para além, buscava também aproximar simbolicamente o poderio régio dos citadinos (ARAÚJO, 2011). A busca era por uma padronização, conforme os mandos régios, entre as vilas da jurisdição, principalmente no que diz respeito às justiças e à administração, deixando suas provisões às câmaras municipais (PEREIRA, 2013). Ou seja, não era uma preocupação, neste momento, o controle da vila com objetivos de centralização político-jurídico-administrativa na metrópole portuguesa; era muito mais uma atitude simbólica que intentava disseminar no sertão da América Portuguesa os costumes e regramentos cultivados em Portugal e nas vilas mais centrais da colônia.

Particularmente à obrigatoriedade das festas religiosas, é possível entrever a estruturação prática da convivência citadina da sociedade corporativa de Antigo Regime ligada ao imaginário religioso. Isso representa, em grande medida, a vinculação às relações de pertencimento desses povoados ao Império Ultramarino Português. Isto é, a religiosidade estimula não só a presença simbólica do rei em todos os territórios de conquistas ${ }^{20}$, estabelecia, ainda, uma linguagem comum construída administrativamente por uma monarquia pluricontinental: a disciplina social católica, o que conferia uma espécie de "uniformidade" ou "apadronamento" entre as localidades.

Em que pese cada local reproduzir costumes e práticas específicos, a dinâmica religiosa, numa espécie de disciplina social, conferia certa dinâmica social assemelhada em todo o império. Ou seja, a religião atua também como uma espécie de regramento de condutas sociais, gerando a reprodução de comportamentos semelhantes entre as vilas e comarcas mesmo que distantes. Não se exclui que a característica de autogoverno bem como as hierarquias sociais costumeiras, traçam histórias sociais diferentes para cada região, mas pode-se afirmar que, por mais diversas que sejam essas trajetórias, têm determinados pontos de conexão. Conforme a perspectiva de João Fragoso e Roberto Guedes (2014, p. 14), "Aqui, não custa insistir na ideia de obediência, pois ela era capaz de exercer o papel dos mecanismos de controle [...]." Essa disciplina, em grande medida, era o que possibilitava, ao mesmo tempo em que fosse mantida a reverência e a subordinação (simbólica e política) ao rei, confundidas com o temor a Deus, ser exercido, no âmbito da localidade camarária, o autogoverno como base dessa monarquia corporativa.

Pode-se afirmar que, a partir do momento em que a Vila de Curitiba passou a fazer parte do Império Ultramarino Português, a comunidade local obteve um considerável crescimento urbano. Sugere-se que o fato de o rei - após noticiado pelo ouvidor em 1720 a respeito da extrema pobreza em que sobreviviam as vilas localizadas no extremo sul da América Portuguesa - ter permitido o comércio com a colônia do Sacramento, e, consequentemente, com a região de Buenos Aires (sobretudo de madeiras, cal de ostras, telha, tijolos e demais frutos da terra), auxiliou em grande escala o desenvolvimento urbano da região (NEGRÃO, v. II, 1906). ${ }^{21}$

Logo após as correições de Pardinho, em 1723, foi criada a Ouvidoria de Paranaguá22, com a finalidade de retirar a competência da Ouvidoria de São Paulo pela parcela sulista da colônia. Assim, foi dividida a Capitania de São Paulo em duas comarcas, instituída a nova Ouvidoria com jurisdição sobre Curitiba, Paranaguá, Cananéia, Iguape, São Francisco, Laguna e, ao longo do século 18, foram elevadas à condição de vila e incorporadas à jurisdição as povoações de Desterro (1726) ${ }^{23}$, Lages (1771), Guaratuba (1771), Castro (1789) e Antonina (1797) (PEGORARO, 2007).

A respeito do vínculo da Vila de Curitiba à Capitania de São Paulo, cabe citar que entre 24 de agosto de 1748 e 8 de agosto $1765^{24}$, o governo "autônomo" de São Paulo foi extinto e permaneceu esta Capitania, constituída pelas Comarcas de São Paulo e Paranaguá, vinculada ao governo do Rio de Janeiro. Nesse período, "O Governador militar da Praça de Santos teve seus poderes ampliados e a sua jurisdição se extendeo a comarca

\footnotetext{
${ }^{20}$ Uma vez que a noção de sociedade corporativa trazia a ideia de que a ordenação natural das coisas era dada por Deus e a pessoa que receberia o dom máximo de toda essa sociedade era o rei.

${ }^{21}$ Sem olvidar o caráter paulatino sustentado por Pereira e Santos (2003).

22 Por Carta Régia de 17 de junho de 1723 a partir de proposta deste mesmo ouvidor (NEGRÃO, v. VIII, 1924). A Ouvidoria da Comarca de Paranaguá foi mantida até 1812, ano em que a sede da comarca foi transferida para Curitiba.

${ }^{23} \mathrm{Em} 1738$ houve a instalação do governo da Ilha de Santa Catarina, e, em 1749, Desterro foi elevada à condição de cabeça de comarca, saindo da jurisdição da Ouvidoria de Paranaguá (PEGORARO, 2007).

${ }^{24}$ Data de acordo com a primeira ordem de Luiz António de Souza, governador da Capitania de São Paulo (NEGRÃO, XIV, 1925).
} 
de Paranaguá e seu districto." (NEGRÃO, v. XII, 1925a, p. 31). Verifica-se que a este governador foram encaminhados instrumentos de administração da justiça, evidência retirada da "Carta Regia sobre collecções das Leis expedidas para Ultramar" de 9 de abril de 1754:

Faço saber a vos governador da Praça de Santos, que por ter mandado formar hua coleção de todas as Leys, Regimentos, e ordens $q^{\prime}$ se tem expedido p.. ultramar, e ser comveniente $p . \underline{a}$ este fim saberse as $q^{\prime}$ tem ido $p . \underline{a}$ esse Governo. Me pareceo ordenarvos, p. $\mathrm{a}$ com a mayor brevidade remetais ao meu conselho ultramarino hû treslado autentico de todas as ditas ordens, Leys, Regimentos, e Alvarãs q' desde o principio desse Governo se expedirão p.a elle, tanto p.․ a bôa administração de minha Fazenda, como da justiça, as quais se hão de achar registadas na Secretaria desse Governo, e repartições de minha Fazenda, ou se consarôm nas ditas partes, e nos Senados da Camera desse Gov. o cuja delligencia vos hey por m. ${ }^{\text {to }}$ recomendado. [...] (NEGRÃO, v. XIII, 1925b, p. 33-34).

Em agosto de 1765 à Capitania de São Paulo, que voltou a possuir governo autônomo, foi nomeado Luiz António de Souza como governador. A este retorno do governo de São Paulo, Francisco Negrão atribui méritos às políticas pombalinas ${ }^{25}$, colocando a ação como objetivo à ocupação da região meridional do território da América Portuguesa.

Neste particular, de fato observam-se, nos Documentos Interessantes para a História e os Costumes de São Paulo, volumes relativos às expedições ao Iguatemy, a Guarapuava e a Tibagy, revelando esforços militares para a ocupação do sertão de Curitiba. Além da coordenação dos movimentos de expedições para o povoamento de novas regiões a oeste, foi também o governador competente em levar às localidades sob sua jurisdição os ensejos metropolitanos.

Remeto a vossas merces a colleção impressa e autentica que comtem a Lei de seis de Mayo do anno proximo preterito de mil sete centos e secenta e sinco, por que Sua Mag. ${ }^{\text {de }}$ que Deus g. de declarou obrepticios, subreptícios e de nenhum efeito pello que pertence aos seos Reinos e Dominios hum breve de nova conformeção do Instituto da Suciedade denominada de Jesus e os seos exemplares: A petição de tecer e o do Procurador da Coroa sobre a matéria decedida na referida Ley. E a carta passada no Real Nome de Sua Magestade a 4 de Mayo do sobredito anno de 1765 em virtude de Alvara de trinta de Abril do referido anno expedido a inztancia do mesmo procurador da Coroa, e imcorporado na dita carta sobre a identidade de forma contextura eteor de cinco Provizois de quatro Loto de outros tantos Regulares da dita Suciedade de que nella se faz menção. [...] E he Sua Mag, de que Deus guarde Sevido, que vossas merces em observância do Alvara de trez de Setembro de 1752 mandem resistar a referida Colleção nos livros de Registo dessa Camera com toda a brevidade, e da mesma sorte que esta dita sem Ihe diminuir nem acreçentarcouza alguma e depois ma fação remeter a Secretaria deste Governo pera ser Registada nas mais Cameras por ser a perpetuidade da mesma muito conveniente ao serviço de Deus e de Sua Magestade, e ao Bem comum e tranquilidade publica destes Reinos e suas conquistas [...] Sam Paullo a 31 de Outubro de 1766. Dom Luiz Antonio de Souza. (NEGRÃO, v. XVI, 1925c, p. 37-38).

No particular das relações entre a Câmara da Vila de Curitiba e os ouvidores de Paranaguá, insta expor que, no período de 1769 a 1777, foram ouvidores Jeronimo Ribeiro de Magalhães (PEGORARO, 2007), nomeado em 1754, e Antonio Barbosa de Matos Coutinho, chancelado em 8 de abril de 1772 e exercente nos anos de 1774 a 1783. Segundo as fontes compiladas no Boletim do Archivo Municipal de Curytiba, Ribeiro de Magalhães teria assumido a ouvidoria de Paranaguá em 10 de maio de 1755 (NEGRÃO, v. XII, 1925a), no entanto

“O grande ministro e extraordinario estadista que foi o Marquez de Pombal, de prompto percebeu a situação política e o grave erro que seus antecessores haviam praticado e o corrigio, restabelecendo o Governo de S. Paulo, com o que integralizou o Brasil já em parte em poder dos Castelhanos. D. Luiz de Souza ao ser investido do cargo de Governador trouxe a missão de fazer a integralização do hinterland da parte meridional do Brasil que se achava em poder, em grande parte, dos hespanhóes. As expedições a Guarapuava e ao Iguatemy, como a fortificação do littoral, fizeram parte do vasto problema politico de Pombal, e as expedições militares de então não tiveram outro caracter." (NEGRÃO, v. XII, 1925a, p. 31). 
seu nome já aparece registrado como ouvidor em documento de 1751, escrito pelo doutor sindicante João Tavares de Abreu. ${ }^{26}$

Oficial português letrado, Ribeiro de Magalhães, conforme documentação contida no Boletim do Archivo Municipal de Curitiba, trouxe ao conhecimento das Vilas sob a jurisdição da Ouvidoria de Paranaguá, a íntegra de determinados atos legislativos editados pelo rei. Assim, dava publicidade aos mandos de D. José I, conforme os Registros de Carta Precatória datados de maio de 1755, e os Provimentos Régios, de outubro de 1754 (NEGRÃO, v. XII, 1925a). Por meio desses documentos, pode-se concluir que a Câmara da Vila de Curitiba recebia, ao menos neste período, notícia das leis e provisões régias. Assim, nessa oportunidade foram publicadas, e direcionadas aos juízes da Câmara de Curitiba, legislações que evidenciam tentativas de mudanças quanto à organização da justiça. É possível identificar nesta passagem, que já havia sido publicada em 19 de outubro de 1754, uma medida que tentou reformar a justiça nos domínios do Império Português.

O Doutor Jeronimo de Magalhais do dezembargo de sua Magestade, que Deus Garde, e seu Ouvidor Geral nesta Comarca de pernagua com alçada pello dito senhor, agora Juiz sindicante do Baxarel $\mathrm{Na}$. ${ }^{\text {to }}$ Pires da Silva e Mello Porto Carreiro Ouvidor que foi da mesma Comarca \&. Faço a saber a todos os senhores Doutores Corregedores, Ouvidores, Provedores, Juízes de fora e ordinario e mais pesoas e oficiais de justiça destes reinos e senhorios de portugal em que elles perante quem os coais esta minha carta precatoria for apresentada, e o verdadeiro conhecimento della se pedir e requerer por calquer forma ou rezão que seja a todos em geral e cada hum em particular em suas jurisdiçoins e em especial aos senhores Juízes ordinarios da villa de Coretiba desta Comarca em como sua Magestade que Deus guarde foi servido em o dia 19 de Outubro de 1754 por mulgarhua Lei sobre a declaração e estenção do para gafôcatorse da re formação da Justiça para se praticarem em todos os seus domínios, ordenandome faça resistar publicar em todas as Cameras desta Comarca e rezistar em a correição della remetendo a sertidão em como asim o cumprio, [...]. Ley por que V. Mag, de ha por bem e manda que a providencia dada no paragrapho 14 da lei e reformação da Justiça para que nos Cazoz que provados merecem pena de morte natural poção prenderce antes de culpa formada etc. Para V. Magestade ver. Seguem-se os respectivos Registros. E nam se continha em a dita precatoria que eu a qui bem e fiel mente a fiz tresladar do proprio original ao que me Reporto e vai na verdade sem cauza de Duvida faça.

Coritiba 27 de Maio de 1755 annos (NEGRÃO, v. XII, 1925a, p. 45-47; v. VIII, 1924, p. 82-95).

A atuação de Magalhães, no entanto, durou apenas até meados da década de 60 do século 18, pois teria sido preso em razão das arbitrariedades que cometera enquanto ouvidor (PEGORARO, 2007). Segundo Francisco Negrão (v. VIII, 1924, p. 82), "Administrou a justiça despoticamente pelo que houveram contra elle diversas representações da Camara de Paranaguá e do Povo.".

Nestes termos, as aparições de Ribeiro de Magalhães como ouvidor ao longo das fontes compiladas no Boletim, ocorrem até o início de $1760^{27}$, mas já em 25 maio do mesmo ano há o nome de Alexandre de Moraes Franco atuando nesse ofício (NEGRÃO, v. XIII, 1925b). Também, em novembro de 1765, Christovão Pinheiro França (NEGRÃO, v. XVI, 1925c) e em março de 1766, João da Silva Pinheiro (NEGRÃO, v. XVI, 1925c). Não foram encontradas, porém, correições movidas por estes oficiais, posto que, entre os Provimentos de Ribeiro de Magalhães e António Barbosa, há:

Seguem-se doze certidões de terem sido lidos os Provimentos aos Juízes e Officiaes da Camara, passadas a e de Junho de 1761, 17 de Setembro de 1762 e 31 de Outubro de 1763 pelo Escrivão Manoel Borges de Sam Payo; de 5 de Janeiro de 1765 e 5 de Janeiro de 1766 pelo Escrivão João Pereira de Azevedo; a 16 de Janeiro de 1767, 2 de Janeiro de 1768, 4 de Fevereiro de 1769, 10 de Janeiro de 1770, 3 de Agt.o de 1771, e de Janeiro de 1772 e 23 de Janeiro de 1773 passadas pelo Escrivão António Francisco Guimaraes, e que por falta de interesse não se reproduzem. F. N. (NEGRÃO, v. VIII, 1924, p. 95).

\footnotetext{
26 "V. ${ }^{\circ}$ em residencia do Ouvidor Jeronimo Rib. ${ }^{\circ}$ de Mag. ${ }^{\text {es }}$ Como S. Mag. de foi servido mandar publicar e registrar Regimento dos Selarios

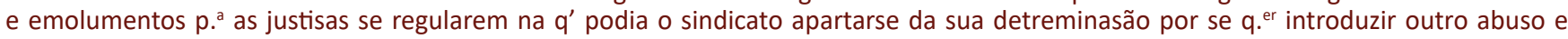
irracionável costume $q^{\prime}$ o d..$^{\circ}$ regimento excluio, e por esta rezão deve restituir o escrivão e meirinho que tem obrigação de não aseitarem mayores esportulas, nem outras que lhe não da a ley a quantia de $\$ \$ 600$ que levarão e se mostra a fls. 110 e 113 repondo as na Camera da Villa de Coretiba. He m. ${ }^{\text {to }}$ preciso examinarse se p. ${ }^{\text {a }}$ esta nova freguesia, Parocho, separasão cobra dos Moradores de S. José do d. ${ }^{\circ}$ da villa de Coretiba houve para ella resolusão e ordem de S. Mag. de sem o que se não deve consentir. Pernaguá 4 de Novembro de 1751 . Abreu" (NEGRÃO, v. VIII, 1924, p. 94-85).

${ }^{27}$ As aparições de Magalhães ocorrem no v. XIII, p. 34, 34-35, 39, 39-40, 40-41, 42, 46 do Boletim.
} 
No período posterior, de 1774 a $1783^{28}$, exercia a função Antonio Barbosa de Matos Coutinho (PEGORARO, 2007). Os provimentos de Barbosa, feitos em 1774, foram, em maioria, no sentido da fixação dos preços, da organização física da Vila e fixação dos rendimentos dos oficiais camarários.

Diante da documentação exposta ${ }^{29}$, o posicionamento tem sido sedimentado no sentido de que, na prática da administração da justiça da localidade da Vila de Nossa Senhora da Luz dos Pinhais de Curitiba, havia a circulação de uma cultura jurídica de nível técnico e sofisticado tanto quanto em vilas maiores e comarcas de importância para a metrópole imperial. Obviamente a aplicabilidade e os estilos não são configurados nos exatos mesmos termos entre o Conselho local e aparatos político-jurídicos de vilas e cidades mais importantes no complexo ultramarino, todavia é possível entrever os esforços dos oficiais locais.

As medidas reformistas mais perceptíveis ao longo da análise da documentação, para além da expulsão dos jesuítas ${ }^{30}$, ocorreram no âmbito administrativo da cidade, principalmente na organização física (predial) da Vila, na instituição de medidas para saneamento e na atuação da polícia, conforme o bando encaminhado pelo governador Luiz António de Souza em 4 de dezembro de 1766:

Dom Luiz Antonio de Souza Mourão digo de Souza Butelho Mourão Morgado de Matheus Fidalgo da Casa de S. Mags. de [...] Governador e Capitão General da Capitania de Sam Paullo. [...] Fasso saver que havendo Sua Magestade que Deus guarde conçiderado o grande numero de vadios e vagabundos que por toda aparte dos Dominios desta America andão grassando ou cometendo horrorosos insultos sem temos de Deos nem das justissas de $\mathrm{S}$. Magestade e transportandoçe de humas Capitanias peras outras pera não poderem ser presos ou vivendo nos Matos sem domicillio certo, ou em citios volantes, onde a maneira de membros podres ou paralictos de corpo humano não são uteis pera o bem comum, nem pera sy tomando este negocio na sua Real consideração fuy servido mandar observar em todos os seus Dominios as Leiz da Pulicia de vinte e cinco de Junho de mil e sete centos e secenta [...] (NEGRÃO, v. XVI, 1925c, p. 33-36).

Também no âmbito econômico, observa Magnus Pereira (2003, p. 21-23), houve estímulo do mercado livre (com os preços dos alimentos sendo tabelados). A exemplo disto, o primeiro provimento da correição do ouvidor António Barbosa de Matos Coutinho, em 15 de janeiro de 1774, estabelece uma padronização dos preços de determinados gêneros alimentícios vendidos na Vila.

Proveo e' de oje em diante não possão os mercadores e Tavernr ${ }^{0 s}[$ [...] de azeite, vinho, vinagre e aguas ardentes vender por outras que não sejão reguladas pelo novo Padrão q' de presente tenho introduzido na cabeça desta Comarca porq' asim se evite a venda de frascos tão prejudicial ao povo, [...] (NEGRÃO, v. VIII, 1924, p. 96).

O mesmo ouvidor determinou aos almotacés medidas de vigilância dos preços, estabelecendo o critério do "racionável" para a fixação desses valores. Ainda, atribuiu ao mesmo oficial a vigilância da limpeza das ruas da Vila, salientando que o cargo camarário da almotaçaria é voltado exatamente às questões de "administração" da Vila no que se refere ao cuidado do espaço físico.

Aos Almotaseis encarrego a observancia do Capitulo 1. sobre a limpeza das ruas, porq' ser este o fim $p . \underline{a} q^{\prime}$ são creados como membros da Camera e a ellesp. ${ }^{\text {arm }}$. ${ }^{\text {te }}$ tocar a provid.. das limpezas das mesmas ruas, asim como de reverem as lojas e fazerem s suas Almotaçarias com regularidade atendendo ao racionavel, preço porq' as coizas se devem vender e não levandosse de paixõens, e efeitos, porq' legd.o a experiencia me mostra ha muito pouco zelo nesta parte, porq' deichão vender tudo como $a$ vond. ${ }^{\text {te }}$ do dono, e vendedor o que praticar pagando os Pobres por hum preço como em alguns dos gêneros se me fez ver, e os ricos pagão pello que querem ou comodam. ${ }^{\text {te }}$ se ajustão e p.. a evitar este dannoja se deve respeitar em bem comum são creadas os Almotaces, Assim Iho encarrego em observancia de sua obrig. ${ }^{\text {ao }}$ penna de lhes aver em culpa toda a omissão.

Barbosa (NEGRÃO, v. VIII, 1924, p. 98).

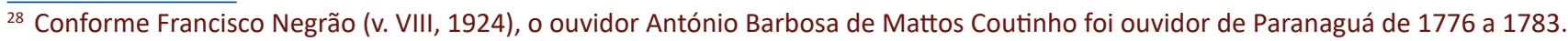

${ }^{29} \mathrm{E}$, também, com embasamento em outras pesquisas desenvolvidas pela autora.

${ }^{30}$ A título de exemplo, há correspondência datada de 3 de setembro de 1768 de Luiz António de Souza encaminhada à Câmara de Paranaguá, ordenando eleição de novo ouvidor, uma vez que o oficial ocupante de tal cargo era padre da Companhia de Jesus e, segundo lei régia de 28 de agosto de 1767, era proibido que jesuítas ocupassem cargos públicos (ARCHIVO DO ESTADO DE SÃO PAULO, v. LXVIII, 1944).
} 
Note-se que, neste mando, o ouvidor utiliza a ideia do "racional" como critério para a fixação dos preços na Vila. Em certa medida, pode ser um reflexo da tentativa de impressão de uma nova compreensão acerca da racionalização nos aparatos administrativos, uma vez que a noção da razão não aparece em passagens anteriores. O critério de ponderação, utilizado anteriormente, é, como excertos já aqui reproduzidos, o bem comum, a saúde e o equilíbrio do reino corporativo.

Esses aspectos do crescimento urbano, entretanto, conforme salienta Pereira (2003), não podem ser confundidos com a introdução na câmara de um embrião iluminista. O direcionamento camarário continuou sendo político, permeado pela moralidade, com representação dos moradores locais, com espaço para que estes realizassem discussões acerca da Vila nos termos das limitações dos regimentos camarários (dos almotacés), elucidados pela mentalidade de ordem conforme a tradição.

\section{CONSIDERAÇÕES FINAIS}

A presente pesquisa prestou a tentativa de, sem qualquer pretensão de esgotamento do tema, verificar ao menos uma parcela do enlace havido entre as características mais importantes entre aquelas reproduzidas no âmbito macro do Império Português e o direcionamento das atuações dos oficiais na colônia. Neste entremeio, tentou-se verificar de que forma se deu essa recepção, bem como se houve repasse às vilas - incluindo questões de como, quando, porque houve recepção e quais foram os motivos da presença ou ausência dos seus reflexos. Imerso no contexto de um encadeamento de fatores existentes no espaço e no tempo recortado, buscou-se o que, de fato, produziu efeito e o que não produziu.

Diante do exposto, é possível afirmar, portanto, que as reformas pombalinas na administração da justiça não ensejaram rupturas na prática do aparelho político-jurídico-administrativo da Vila de Nossa Senhora da Luz dos Pinhais de Curitiba nos períodos de 1769 a 1777. A título de explicação dessa questão, levanta-se um posicionamento: o modo da administração da justiça em Curitiba não sofreu rupturas no período pombalino por estar concentrado num organismo conselhio que, imerso no imaginário e no simbolismo de pertencimento ao Império Ultramarino Português, buscou estar na mesma esteira do que se acreditava ser aplicado no restante do Império. Ou seja, a tentativa de estar de acordo com o que se imaginava estar correto em relação à metrópole, fez com que os oficiais camarários da Vila prestassem grande parte de suas ações em consonância com as Ordenações, com a legislação extravagante e com os mandos régios de que tinham conhecimento por meio da Ouvidoria de Paranaguá e do governo da Capitania de São Paulo. Ainda, neste auxílio, havia leitura anual dos Provimentos deixados pelo Ouvidor de São Paulo, Raphael Pires Pardinho, o que vem ao encontro do pensamento de que, de fato, os oficiais buscavam estar em consonância com o padrão imperial. Revela-se, assim, uma região na qual as regras gerais e o direito consuetudinário se inter-relacionavam.

A forma pulverizada de colonização, embasada em instituições locais, no modelo monárquico corporativo (HESPANHA, 1994) - impresso nele o simbolismo atrelado à imagem do rei - trazido à América Portuguesa, fez com que o vínculo estabelecido entre os súditos e o rei fosse forte de tal forma a remoldar uma organização social, em que os detentores de ofícios da justiça eram de grande importância ao governo corporativo do ultramar português (SCHWARTZ, 2011). ${ }^{31}$

Por derradeiro, registre-se que esta exposição não ensejou o esgotamento do tema, sobretudo no que se refere às leituras da documentação histórica disponível. Embora ainda existam caminhos em aberto a serem percorridos, o apontamento a que se direciona até o presente momento é o de que o braço, formalmente considerado, das reformas na administração da justiça, não alcançara de modo abrupto e direto a região coIonial em que se situava a Vila de Curitiba. Não se pode olvidar, todavia, que, politicamente, mesmo que de forma bastante indireta e paulatina, a reprodução de atividades no sentido de uma administração mais ativa da vida citadina se fez sentir na região colonial da Vila de Nossa Senhora da Luz dos Pinhais de Curitiba.

\footnotetext{
${ }^{31}$ A própria configuração da sociedade corporativa de Antigo Regime era muito vinculada às relações de pertencimento desses povoados ao Império Ultramarino Português, estimuladas pela presença simbólica do rei em todos os territórios de conquistas. Ainda, havia uma linguagem comum construída administrativamente por uma monarquia pluricontinental: a disciplina social católica, o que conferia uma espécie de "uniformidade" ou "apadronamento" entre as localidades. Isto é, em que pese cada local reproduzir costumes e práticas específicos, a dinâmica religiosa, numa espécie de disciplina social, conferia certa dinâmica social assemelhada em todo o império. Isso possibilitava que a subordinação às autoridades, e especialmente ao rei, "fosse confundida com o amor a Deus. Mas também possibilitava que o autogoverno dos municípios fosse a base da monarquia polissinodal e corporativa" (FRAGOSO; GUEDES, 2014, p. 21).
} 


\section{REFERÊNCIAS}

ANTUNES, A. de A. Pelo rei, com razão: sobre as reformas pombalinas no campo jurídico. Revista do Instituto Histórico e Geográfico Brasileiro, n. 452, p. 15-50, 2011.

ARAÚJO, D. R. W. A Almotaçaria e o direito na Vila de Curitiba (1737-1828). 2011. Dissertação (Mestrado em Direito) - Universidade Federal do Paraná, Setor de Ciências Jurídicas, Curitiba, 2011.

ARCHIVO DO ESTADO DE SÃO PAULO. Publicação de documentos interessantes para a história e costumes de S. Paulo. São Paulo: Tipografia do Globo, 1940. V. LXV, LXVIII, LXXVII.

ARCHIVO DO ESTADO DE SÃO PAULO. Publicação de documentos interessantes para a história e costumes de S. Paulo. São Paulo: Typographia Andrade \& Mello, 1944. V. LXVIII.

ARCHIVO DO ESTADO DE SÃO PAULO. Publicação de documentos interessantes para a história e costumes de S. Paulo. São Paulo: Typographia Andrade \& Mello, 1954. V. LXXVII.

BICALHO, M. F. B. As câmaras ultramarinas e o governo do Império. In: FRAGOSO, J. (org.). O antigo regime nos trópicos: a dinâmica imperial portuguesa (séculos XVI-XVIII). Rio de Janeiro: Civilização Brasileira, 2001.

BICALHO, Maria Fernanda. Da colônia ao império: um percurso historiográfico. In: BICALHO, Maria Fernanda; FURTADO, Júnia Ferreira; SOUZA, Laura de Mello e (orgs.). O governo dos povos. São Paulo: Alameda, 2009.

BICALHO, M. F. B.; FURTADO, J. F.; SOUZA, L. de M. e (org.). O governo dos povos. São Paulo: Alameda, 2009.

BORGES, J. N. Das justiças e dos litígios; a ação judiciária da Câmara de Curitiba no século XVIII (1731-1752). 2009. Tese (Doutorado em História) - Universidade Federal do Paraná, Setor de Ciências Humanas, Letras e Artes, Curitiba, 2009.

BOXER, C. O Império marítimo português: 1415-1825. São Paulo: Companhia das Letras, 2008.

CARVALHO, E. T. de. Verney e a questão do Iluminismo em Portugal. 2005. Dissertação (Mestrado em História) - Universidade Federal do Paraná, Setor de Ciências Humanas Letras e Artes, Curitiba, 2005.

COSTA, Mário Júlio de Almeida. História do Direito Português. Coimbra: Almedina, 1996

FRAGOSO, J. L. R.; GUEDES, R. Apresentação: notas sobre transformações e a consolidação do sistema econômico do Atlântico Iuso no século XVIII. In: FRAGOSO, J. L. R.; GOUVÊA, M. de F. O Brasil Colonial. Rio de Janeiro: Civilização Brasileira, 2014. V. 3.

FURTADO, Júnia Ferreira. Diálogos oceânicos: Minas Gerais e as novas abordagens para o império marítimo português no século XVIII. In: BICALHO, Maria Fernanda; FURTADO, Júnia Ferreira; SOUZA, Laura de Mello e (org.). O governo dos povos. São Paulo: Alameda, 2009.

GROSSI, P. Mitologias jurídicas da modernidade. Florianópolis: Fundação Boiteux, 2007.

GROSSI, P. Para além do subjetivismo jurídico moderno. In: FONSECA, R. M.; SEELANDER, A. C. L. (org.). História do direito em perspectiva. Curitiba: Juruá, 2008.

HESPANHA, A. M. Às vésperas do Leviathan: instituições e poder político. Portugal - séc. XVII. Coimbra: Livraria Almedina, 1994.

HESPANHA, A. M. Cultura jurídica europeia: síntese de um milênio. Florianópolis: Fundação Boiteux, 2005.

MARCOS, R. M. de F. A legislação Pombalina: alguns aspectos fundamentais. Coimbra: Livraria Almedina, 2006.

MAXWELL, K. Marquês de Pombal: paradoxo do iluminismo. Rio de Janeiro: Paz e Terra, 1996.

MONTEIRO, N. Trajetórias sociais e governo das conquistas: Notas preliminares sobre os vice-reis e governadores-gerais do Brasil e da Índia nos séculos XVII e XVIII. In: FRAGOSO, João (org.). O antigo regime nos trópicos; a dinâmica imperial portuguesa (séculos XVI - XVIII). Rio de Janeiro: Civilização Brasileira, 2001.

NEGRÃO, F. (ed.). Boletim do Archivo Municipal de Curytiba. Documentos para a história do Paraná. Curitiba: Impressora Paranaense, 1906. V. I.

NEGRÃO, F. (ed.). Boletim do Archivo Municipal de Curytiba. Documentos para a história do Paraná. Curitiba: Impressora Paranaense, 1906. V. II.

NEGRÃO, F. (ed.). Boletim do Archivo Municipal de Curytiba. Documentos para a história do Paraná. Curitiba: Impressora Paranaense, 1908. V. VI.

NEGRÃO, F. (ed.). Boletim do Archivo Municipal de Curytiba. Documentos para a história do Paraná. Curitiba: Livraria Mundial, 1924. V. VIII.

NEGRÃO, F. (ed.). Boletim do Archivo Municipal de Curytiba. Documentos para a história do Paraná. Curitiba: Impressora Paranaense, 1925a. V. XII.

NEGRÃO, F. (ed.). Boletim do Archivo Municipal de Curytiba. Documentos para a história do Paraná. Curitiba: Impressora Paranaense, 1925b. V. XIII. 
NEGRÃO, F. (ed.). Boletim do Archivo Municipal de Curytiba. Documentos para a história do Paraná. Curitiba: Impressora Paranaense, 1925c. V. XVI.

NEGRÃO, F. (ed.). Boletim do Archivo Municipal de Curytiba. Documentos para a história do Paraná. Curitiba: Impressora Paranaense, 1927. V. XXXI.

PEGORARO, J. W. Ouvidores régios e centralização jurídico-administrativa na América portuguesa: a Comarca de Paranaguá (1723-1812). 2007. Dissertação (Mestrado em História) - Setor de Ciências Humanas, Letras e Artes, Universidade Federal do Paraná, Curitiba, 2007.

PEREIRA, L. F. L. Estruturas político-jurídicas na América Portuguesa: entre centro e periferia. Primer Encuentro Latino Americano de Historia del Derecho y la Justicia. Cidade do México: Historia del Derecho y la Justicia, 2009.

PEREIRA, L. F. L. O Império Português: a centralidade do concelho e da cidade, espaço da cultura jurídica. In: FONSECA, R. M. (org.). As Formas do Direito. Ordem, Razão e Decisão. Curitiba: Juruá, 2013.

PEREIRA, M. R. de M. O direito de almotaçaria. In: PEREIRA, M. R. de M.; NICOLAZZI JR., N. F. (org.). Audiências e correições dos almotacés (Curitiba, 1737 a 1828). Curitiba: Aos Quatro Ventos, 2003.

PEREIRA, M. R. de M.; SANTOS, A. C. de A. Códigos de posturas municipais. In: PEREIRA, M. R. de M. (org.). Posturas municipais - Paraná, 1829 a 1895. Curitiba: Aos Quatro Ventos, 2003.

PORTUGAL. Estatutos da Universidade de Coimbra do ano de 1772. L. II. Lisboa: Regia Officiona Typografica, 1772.

PORTUGAL. Lei de 18 de agosto de 1769. In: PORTUGAL. Collecção da Legislação Portugueza desde a ultima compilação das Ordenações, redigida pelo Desembargador Antonio Delgado da Silva. Legislação de 1763 a 1774. Lisboa: Typografia Maigrense, 1829.

PORTUGAL. Ordenações Filipinas. 14. ed. (Recompiladas por Candido Mendes de Almeida). Rio de Janeiro: Typographia do Instituto Philomathico, 1870.

SANTOS, Antonio Cesar de Almeida (org.). Provimentos do ouvidor Pardinho para Curitiba e Paranaguá (1721). Curitiba: Monumenta, 2000.

SANTOS, Rosângela Maria Ferreira dos; SANTOS, António Cesar de Almeida (org.). Eleições da Câmara Municipal de Curitiba (1748 a 1827). Curitiba: Aos Quatro Ventos, 2003.

SBRICCOLI, M. Giustizia criminale. In: SBRICCOLI, M. Storia del diritto penale e dela giustizia. Milano: Giuffrè Editore, 2009. Tomo I.

SCHWARTZ, S. B. Burocracia e sociedade no Brasil Colonial: o Tribunal Superior da Bahia e seus desembargadores, $1609-1751$. São Paulo: Companhia das Letras, 2011.

SEELAENDER, A. C. L. A "polícia" e as funções do Estado. Notas sobre a "Polícia" do Antigo Regime. Revista da Faculdade de Direito UFPR, n. 49, 2009.

SILVA, N. J. E. G. da. História do Direito Português. Fontes de Direito. Lisboa: Fundação Calouste Gulbenkian, 2000.

SUBTIL, J. Governo e administração. In: MATTOSO, J. (dir.); HESPANHA, A. M. (coord.). História de Portugal Vol. IV. O antigo regime (1620-1807). Lisboa: Editorial Estampa, 1998.

WEHLING, A.; WEHLING, M. J. Formação do Brasil Colonial. Rio de Janeiro: Nova Fronteira, 1999. 